\title{
Youth self-report of child maltreatment in representative surveys: a systematic review
}

Jessica Laurin*, MA; Caroline Wallace ${ }^{*}$ BSc; Jasminka Draca, BHSc; Sarah Aterman, BAH; Lil Tonmyr, PhD

This evidence synthesis has been peer reviewed.

\begin{abstract}
Introduction: This systematic review identified population-representative youth surveys containing questions on self-reported child maltreatment. Data quality and ethical issues pertinent to maltreatment data collection were also examined.

Methods: A search was conducted of relevant online databases for articles published from January 2000 through March 2016 reporting on population-representative data measuring child maltreatment. Inclusion criteria were established a priori; two reviewers independently assessed articles to ensure that the criteria were met and to verify the accuracy of extracted information.
\end{abstract}

Results: A total of 73 articles reporting on 71 surveys met the inclusion criteria. A variety of strategies to ensure accurate information and to mitigate survey participants' distress were reported.

Conclusion: The extent to which efforts have been undertaken to measure the prevalence of child maltreatment reflects its perceived importance across the world. Data on child maltreatment can be effectively collected from youth, although our knowledge of best practices related to ethics and data quality is incomplete.

Keywords: abuse, neglect, violence, data quality, ethics, adolescence, teenager, systematic review

\section{Introduction}

The consequences of child maltreatmenta public health issue that poses unique challenges to quantify and study-extend well beyond the immediate harm inflicted. For example, a history of child maltreatment has been shown to interfere with adolescent development and to raise the risk of some of the leading causes of morbidity and mortality. ${ }^{1}$ These include alcohol-related injury, drug use, selfharming behaviour, suicide and exposure to violence. ${ }^{2-5}$

A growing body of research is aimed at estimating the extent of child maltreatment, and understanding the dynamics and mechanics of its association with health outcomes. ${ }^{6}$ Population-representative surveys provide the opportunity to quantify child maltreatment prevalence and to assess its risk in relation to other healthrelated and social conditions. Of course, in surveys that address a broad range of health-related content, space limitations and competing interests challenge the inclusion of child maltreatment measures. However, the potential contribution of such surveys in improving our understanding of the prevalence, risk factors and impact of child maltreatment is becoming increasingly appreciated-both in Canada and elsewhere. ${ }^{7}$ Populationbased data from other countries provide the basis for international comparisons, from which the influence of cultural, social and policy practices on any differences observed can be considered. ${ }^{8,9}$

The ethical aspects of child maltreatment survey research are crucial. The sensitive nature of the subject matter and the consequential risk of emotional distress to

\section{Highlights}

- Data on child maltreatment can be collected responsibly and ethically from youth in a way that protects their health and well-being.

- Youth rarely expressed concerns about answering child maltreatment questions on self-report surveys.

- No nationally representative selfreport survey focussed on Canadian youth that includes child maltreatment variables was identified from our database search.

- Few reliable and valid self-reported measures of child maltreatment currently exist.

respondents call for measures to protect confidentiality, administer questions with appropriate sensitivity, obtain informed consent, and potentially provide follow-up interventions. ${ }^{10}$ Procedures to address such matters should be clearly delineated, and included as an elemental component of any survey or research report.

Quality of data is an important consideration and should be evaluated in any survey-based research on child maltreatment. Various factors influence the quality of information a respondent provides, such as age and developmental stage. Surveying young people about experiences of child maltreatment has the advantage of being relatively recent to the exposure, so recall bias is likely lower than it would be in a survey of adults. The reliability of selfreported information from adolescents is greater than that from younger children, by virtue of their more advanced cognitive development. ${ }^{11}$ Specifically, research suggests that children under the age of 10 years may not be reliable respondents

\section{Author reference:}

Public Health Agency of Canada, Ottawa, Ontario, Canada

* These authors contributed equally to this work.

Correspondence: Lil Tonmyr, Public Health Agency of Canada, 785 Carling Ave, $7^{\text {th }}$ floor, Ottawa, ON K1A 0K9; Tel: 613-240-6334; Email: Lil.Tonmyr@canada.ca 
for a survey on experiences of maltreatment. ${ }^{12}$ Other potential impediments to the disclosure of accurate information include distress, discomfort and embarrassment generated by the memory of events. ${ }^{13-16}$

A review article published in 2000 addressed methodological and ethical considerations in asking children about their exposure to physical and sexual abuse. ${ }^{17}$ The authors identified 14 selfreport studies that garnered information directly from children; the approaches used to elicit information varied greatly. ${ }^{17}$ While the review provides much worthwhile information, it was limited to surveys conducted before 1999; the surveys focussed on physical and sexual abuse and were not representative of the general population. The authors noted considerable variation in data collection methods, wording and number of maltreatment questions as well as consent procedures. Consequently, the estimates of physical and sexual abuse varied considerably.

This systematic review is aimed at increasing our understanding of child maltreatment data captured in self-reported surveys with youth. The specific objectives are to (1) identify representative surveys that have collected data from youth on child maltreatment and factors influencing prevalence (thus not clinical samples); (2) examine the quality of methods used to measure child maltreatment; and (3) assess practices and procedures undertaken to address ethical issues.

\section{Methods}

This systematic review was done according to the PRISMA guidelines. ${ }^{18}$ (Protocol is available upon request from the corresponding author).

\section{Identification (search strategy)}

A search for peer-reviewed articles published from January 2000 through March 2016 was conducted in the following online databases: Embase, Medline, PsycINFO, Global Health, Social Policy and Practice, ERIC, Social Services Abstracts, Sociological Abstracts, and ProQuest Public Health. Search terms used included: youth, adolescent, young adult, child, abuse, maltreatment, violence, neglect, assault, rape, representative, national, and school surveys. The complete search strings employed are available upon request from the corresponding author. In addition, the reference lists of included articles were examined to identify additional articles for potential inclusion as well as discussions with experts.

The following were the criteria for inclusion of articles in the review:

- published in English;

- primary study (i.e. not review or editorial);

- data collected after 1999;

- data sources limited to school or representative population-based surveys (the latter defined as those which were described that way by the authors of the articles and/or had been sampled and weighted in order to accurately reflect the members of the entire population);

- cross-sectional design;

- age range of respondents was 10 to 18 years (core age group); in some cases, age ranged up to 24 years;

- victim's age at time of exposure to maltreatment was under 18 years;

- reported perpetrator of maltreatment was a parent or other caregiver (except for sexual abuse, for which the perpetrator could be anyone, however articles were still not included if they focused on peer or online victimization);

- analysis was conducted using the entire sample of the specified age group (ages 10 to 18).

It should be noted that we limited the inclusion to cross-sectional studies to ensure the inclusion of the largest numbers of surveys. In addition, since the primary purpose of this article is not to determine associations but instead the feasibility of collecting child maltreatment data from youth to estimate prevalence, cross-sectional studies are appropriate. The benefit of including longitudinal studies would be limited, considering that child maltreatment questions are rarely asked in the first wave of a longitudinal study but rather in the later waves where attrition may be an issue. ${ }^{19,20}$

\section{Screening/eligibility (selection process)}

Figure 1 shows the process of selecting the articles included in this study. The database search identified 4383 articles; expert consultation and search of reference lists identified another 31 articles. Removing duplicates yielded 3885 articles, and screening by titles and abstracts led to 220 articles to be fully assessed. To these articles, the inclusion criteria noted above were applied by two reviewers independently (J.L., L.T.). The percentage agreement between the coder pairs was $97.9 \%$ for titles and abstracts. Articles were excluded when the articles addressed adults' retrospective reports of childhood maltreatment, substance abuse, non-representative samples, newspaper articles, conference abstracts, commentaries, and letters to the editor. Each reviewer also catalogued the reported prevalence of maltreatment by type. Although specific definitions of child maltreatment varied somewhat among the articles, they were conceptually similar enough that the Public Health Agency of Canada's (PHAC) classifications could be applied such as emotional maltreatment (EM), neglect (NG), exposure to intimate partner violence (EIPV), physical and sexual abuse (PA and SA) ${ }^{21}$ (Table 1).

We modified a coding key previously used in assessing adults' retrospective exposure to childhood maltreatment. ${ }^{6}$ Reliability and validity of the maltreatment measures were noted when reported. Documentation of procedures related to ethics focused on any steps taken to protect confidentiality, offer respondents support, or ease their distress during/following the survey (see Table 2). Information related to survey administration and measures to evaluate data quality were collected from the articles. As well, external sources (e.g. articles or websites) cited in the articles were consulted for information regarding validity and reliability of child maltreatment measures; in some cases, these sources also provided insights into how maltreatment was conceptualized for a survey, or clarified survey procedures. When information in an article included in the review was inconsistent with that provided in an external source, the former took precedence; if information in articles selected for review and pertaining to the same survey conflicted, the article more closely addressing the objectives of the study was used.

As a final step, to verify that the selected articles met the inclusion criteria and to ensure the accuracy of all extracted information, the articles were assessed by two additional reviewers (C.W., S.A., or J.D.); 


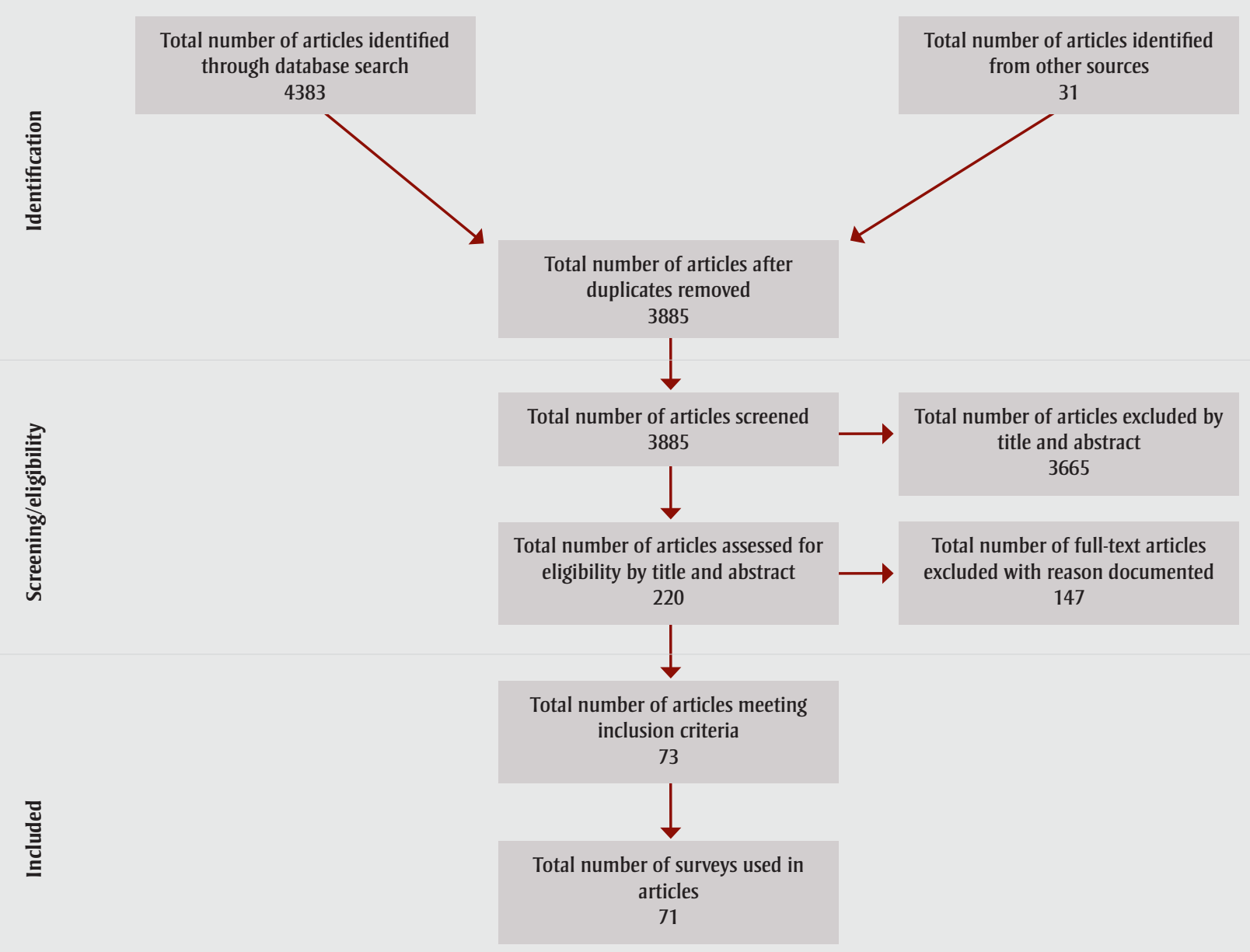

any disagreements were discussed until consensus was reached.

\section{Results}

From the 3885 articles identified in the online search, 220 were screened in according to the abstract and title. Of these, 73 met the inclusion criteria, representing 71 surveys. Table 3 describes the characteristics of each sample, survey methodology, measures of child maltreatment, reliability and validity, response rates and any steps taken to enhance the response rate, approaches and protocols designed to comfort or reduce the distress of participants, and types of child maltreatment. Schools were most often the place of data collection. Most data were collected via self-administered questionnaire, data were also provided by face-toface and telephone interviews independent of location. Eleven measures were used and often modified from the original iteration. The Juvenile Victimisation Questionnaire (JVQ) was used most often (eight times), followed by different versions of the Conflict Tactics Scale (CTS) (six times) and the International Society for the Prevention of Child Abuse and Neglect child abuse screening tool-Child (ICAST-CH) (four times). Thirty-seven articles did not provide any information on the specific measures used. In addition, few articles provided information regarding the reliability and validity of measures used. Respondents' response rates ranged from $40.4 \%$ to $99.9 \%$. The majority of articles mentioned approaches taken to comfort respondents, although specific information on procedures to reduce distress was scarce.

The most commonly mentioned procedures in place for reducing or dealing with participant distress were as follows:
(1) providing respondents with information and telephone numbers of appropriate support services; (2) following up with respondents who disclosed threatening situations; (3) giving focused, sensitivity training to interviewers; (4) alerting appropriate authorities when intervention was deemed necessary. Of course, disclosure to participants of the possibility of alerting authorities could negatively influence participation.

Of the maltreatment types, sexual abuse was captured most frequently in the survey questions (see Table 3 ). The majority of maltreatment measures specified behaviours, rather than being self-defined; sexual abuse was stipulated with the most detail. Child maltreatment prevalence estimates varied by measure and were not always reported. The heterogeneity of measures and variation in time periods covered precluded meaningful comparisons 
TABLE 1

Definition of child maltreatment

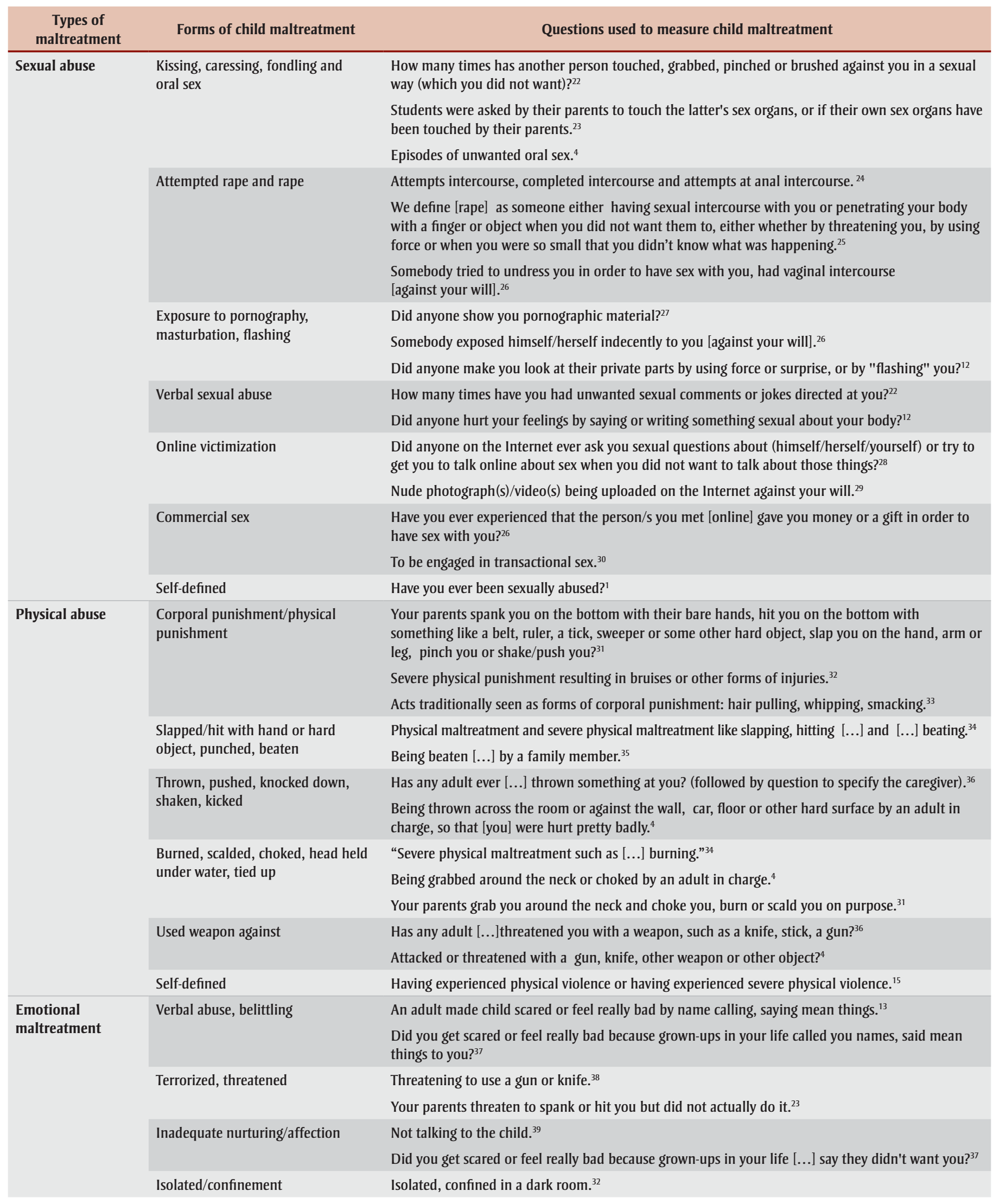


TABLE 1 (continued)

Definition of child maltreatment

\begin{tabular}{|c|c|c|}
\hline $\begin{array}{c}\text { Types of } \\
\text { maltreatment }\end{array}$ & Forms of child maltreatment & Questions used to measure child maltreatment \\
\hline \multirow[t]{3}{*}{ Neglect } & Supervisory & Having inadequate supervision and being required to do age-inappropriate chores. ${ }^{40}$ \\
\hline & & Not receiving adequate food or clothing. ${ }^{40}$ \\
\hline & Medical & $\begin{array}{l}\text { When someone is neglected it means that the grown-up in their life did not take care of them the } \\
\text { way they should [...] [by] taking them to the doctor when they are sick. }{ }^{37}\end{array}$ \\
\hline \multirow{4}{*}{$\begin{array}{l}\text { Exposure to } \\
\text { intimate partner } \\
\text { violence }\end{array}$} & Physical abuse & The young person witnessed his/her parents physically abusing each other. ${ }^{41}$ \\
\hline & & $\begin{array}{l}\text { Adolescent observed parents punched, hit or beat up one another, choked one another, hit one } \\
\text { another with an object. }\end{array}$ \\
\hline & Emotional maltreatment & Asked whether if they had ever [...] witnessed severe arguments between their parents. ${ }^{2}$ \\
\hline & & Adolescent observed parents [...] threatening one another with gun, knife or other weapon. ${ }^{4}$ \\
\hline
\end{tabular}

of prevalence estimates. Summary estimates for lifetime prevalence ranged from $0.3 \%$ to $44.3 \%$ for sexual abuse, $4.2 \%$ to $58.3 \%$ for physical abuse, $3.1 \%$ to $78.3 \%$ for emotional maltreatment, $0.9 \%$ to $38.3 \%$ for neglect, and $0.6 \%$ to $30.9 \%$ for exposure to intimate partner violence.

\section{Discussion}

The findings of this systematic review reflect the extensive effort that has been made to measure child maltreatment at the population level and thus the perceived importance of this problem across the world. The review identified a variety of strategies employed to enhance data accuracy and mitigate participants' distress. Our findings were similar to those found in the review from 2000. ${ }^{17}$ However, both our findings and theirs demonstrate that information on child maltreatment can be collected, albeit the issue of inconsistent definitions remains.

\section{Identifying surveys and factors influencing prevalence estimates}

Prevalence estimates of child maltreatment varied widely among the studies examined. In assessing findings across surveys, it is important to consider factors intrinsic to self-reporting that can compromise comparability. ${ }^{24}$ Barriers include self-blame, cognitive development and age, stigma, fear of retaliation by the perpetrator, and failure to recognize behaviour as abusive. ${ }^{16}$ Regarding the latter, differing perceptions of what constitutes discipline versus abuse can contribute to inconsistencies in response. ${ }^{8}$ In some cultures, the use of physical punishment is commonplace and even legally accepted, ${ }^{31,39}$ while in others it is considered to be abuse. $^{109}$ In some studies, behaviours related to sexual abuse were not assessed because the topic was deemed too culturally sensitive. ${ }^{50,60}$

Variations in prevalence estimates of child maltreatment across studies might also be

TABLE 2

Approaches to increase respondent's comfort and response rate

\section{Definitions}

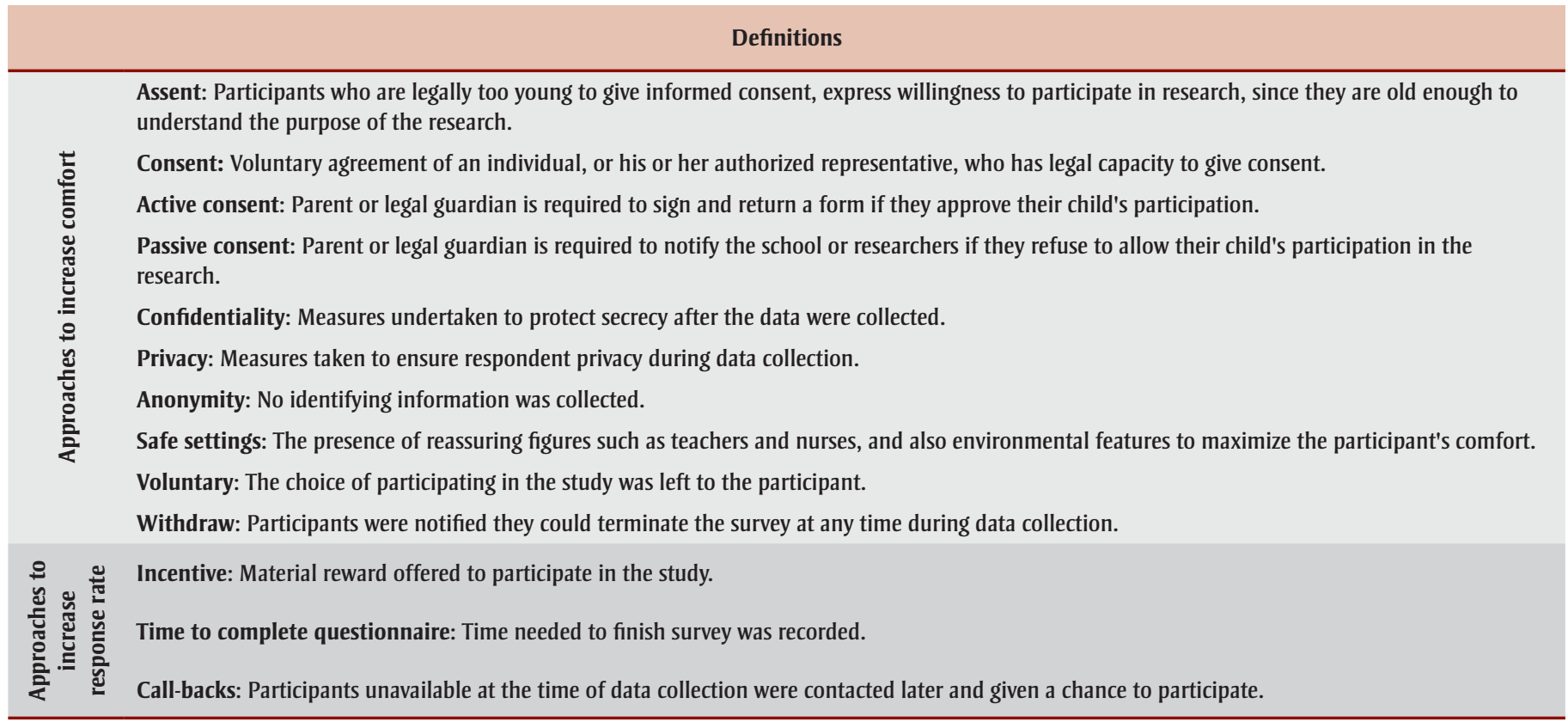




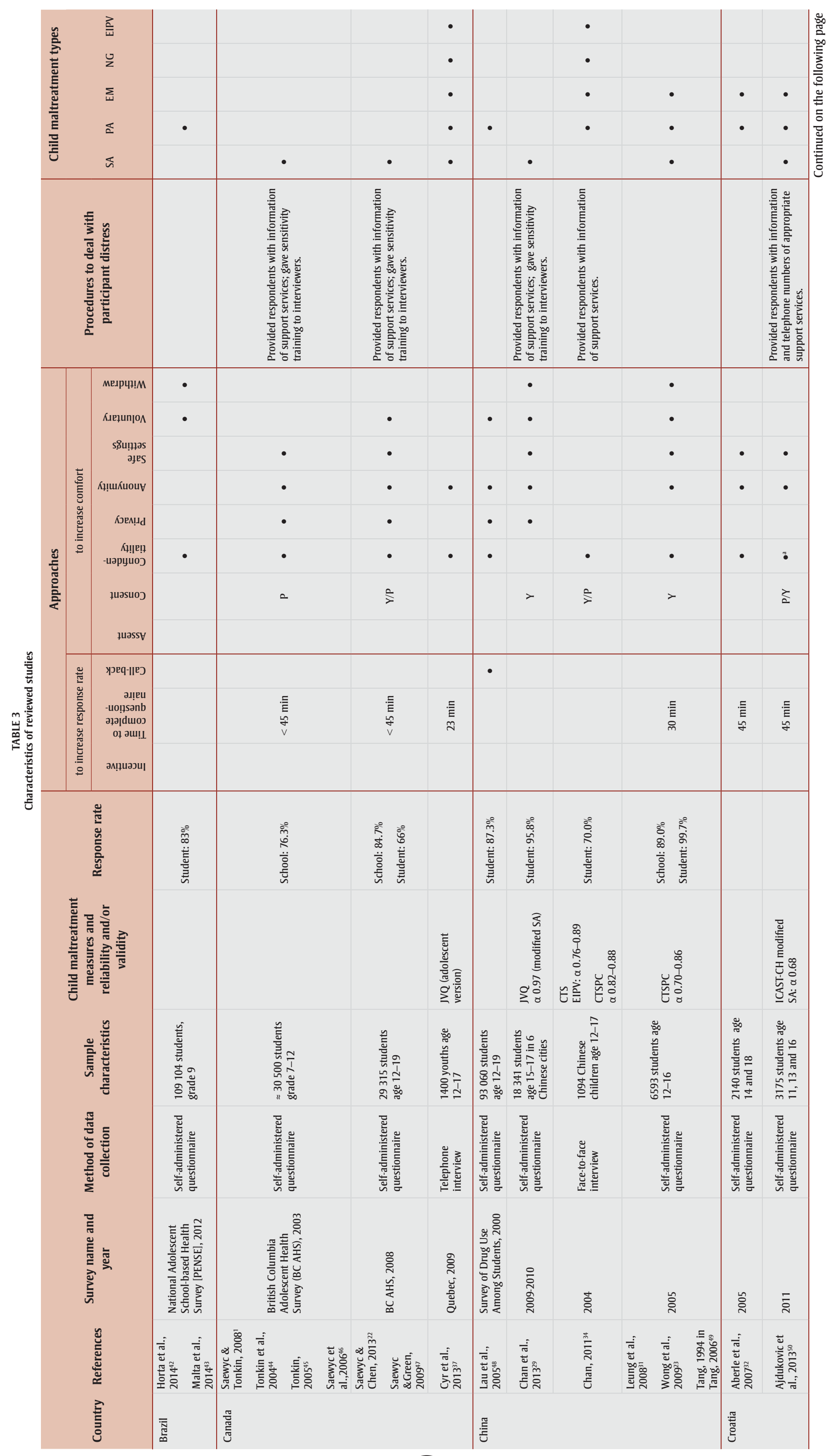




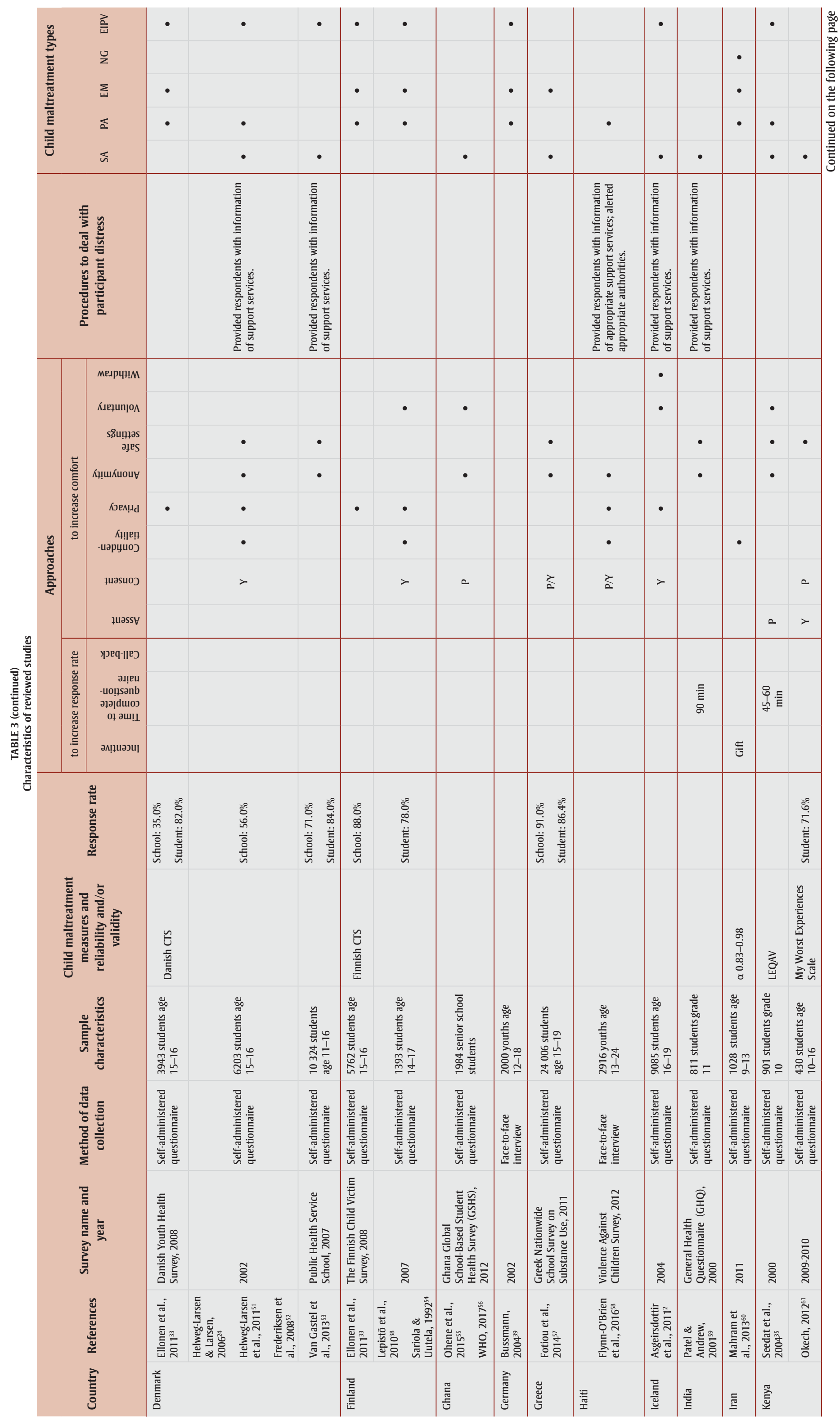




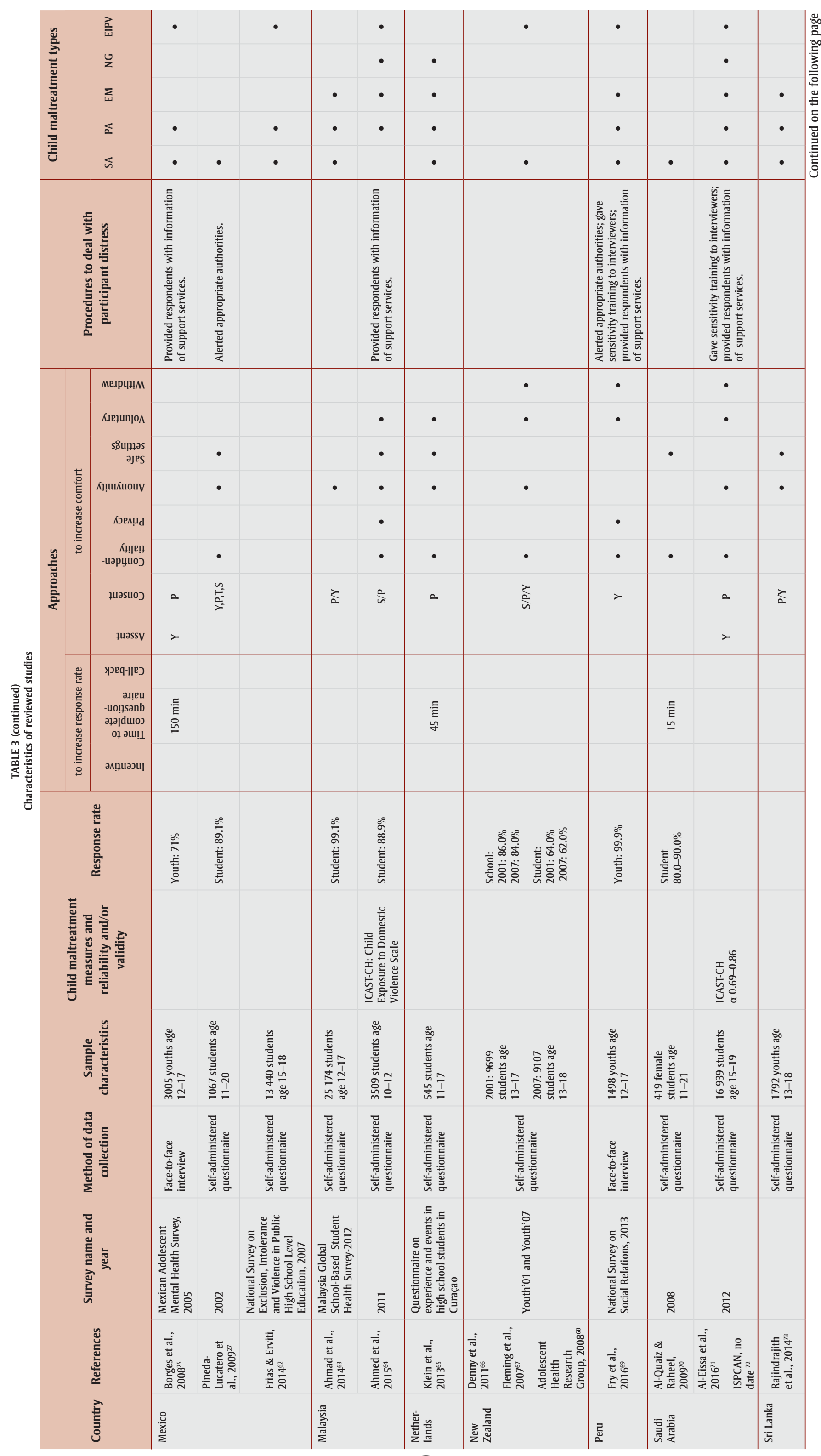




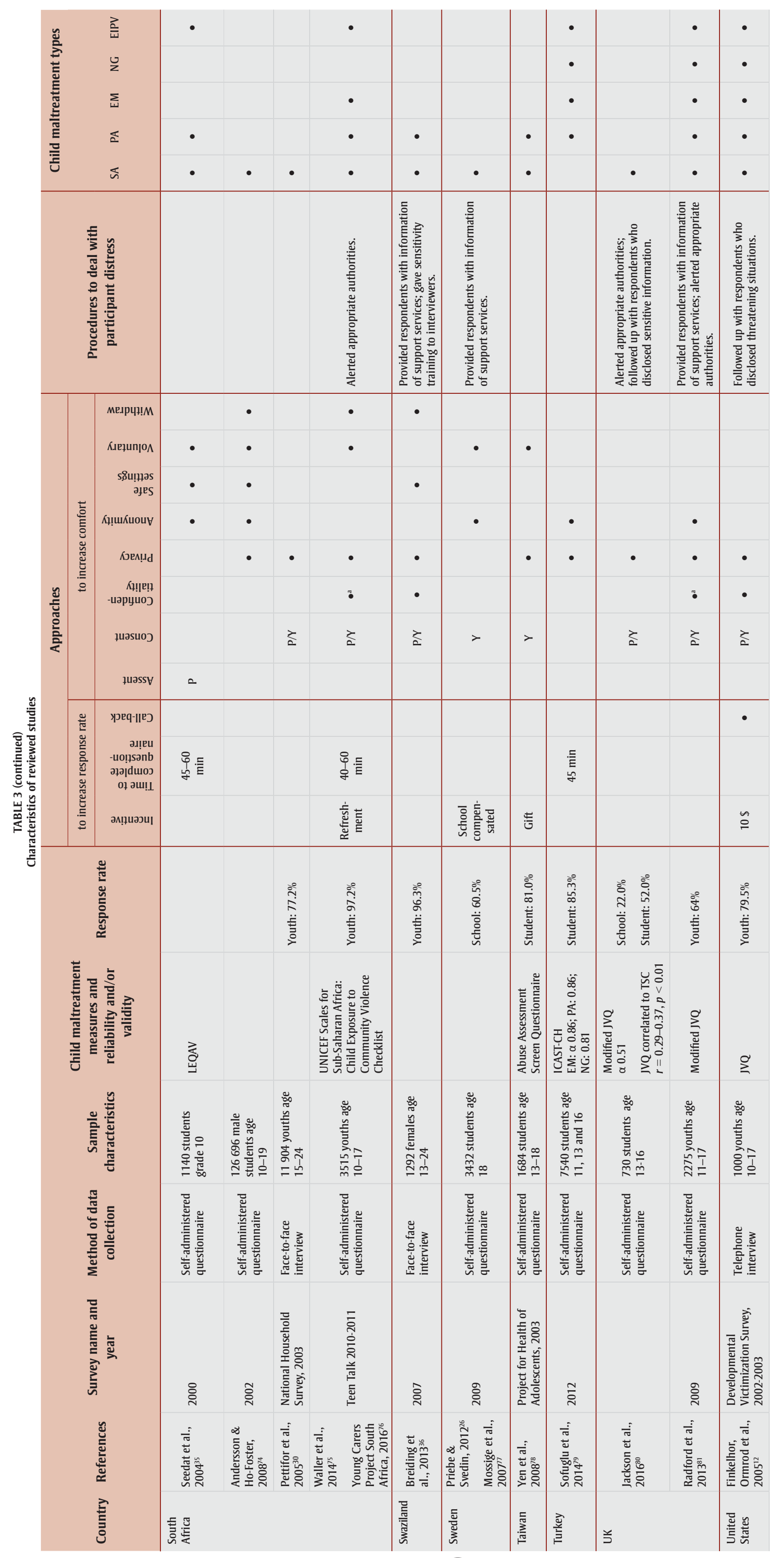




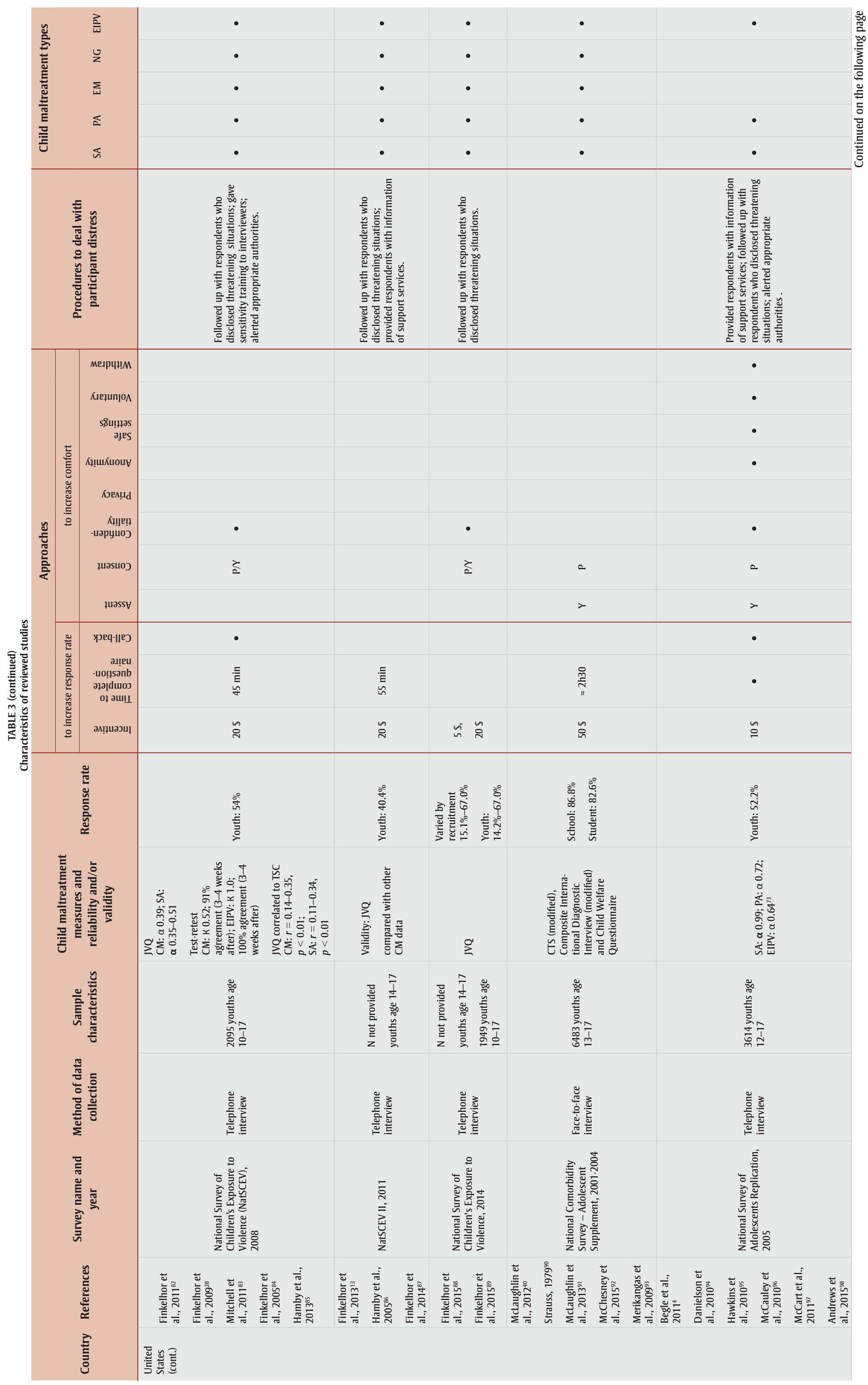




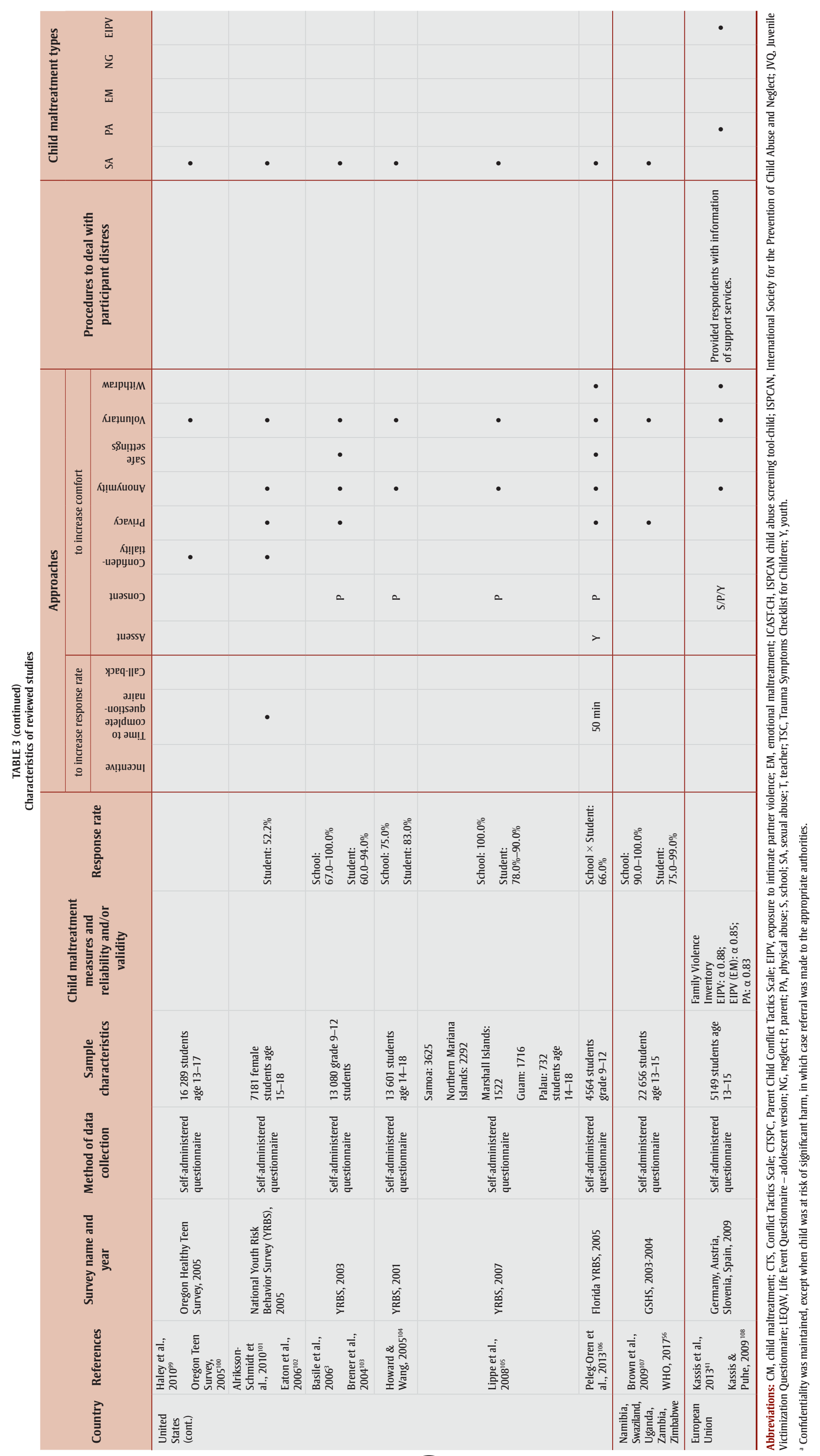


attributable to differences in measures. For example, with the objective of encouraging disclosure of sexual abuse, some surveys stipulate specific behaviours, ${ }^{3}$ while others use more generally-worded questions. ${ }^{101}$ Some measures of maltreatment are dichotomous (yes-no), in contrast to others that ask for details on severity and frequency.

Dissimilarities in conceptual scope can also influence prevalence estimates. For example, some but not all surveys explicitly include online victimization as a component of sexual abuse. Finally, the particular vocabulary used to describe specific behaviours may also impact comparability. For example, the expression, "forced sex without consent," might be interpreted more broadly than "rape," and thus be more apt to elicit a positive response (and increase apparent prevalence). Neglect was measured in only a few surveys-perhaps reflecting the challenges inherent to capturing it in population surveys. In some communities, relatively lower estimates of neglect were attributable to close social networks and living arrangements. ${ }^{65}$ Efforts to improve the collection of data on neglect in population-based surveys and from young respondents are currently under way. ${ }^{110,111}$

\section{Quality of data}

The majority of the articles examined provided no detailed information on the reliability or validity of measures used within surveys. Statements such as "the reliability of the scale has been well-documented," or indicating that validity had been determined by the authors, were common but not fully informative. Unfortunately, only three articles reported validity..$^{80,84,87}$ In terms of reliability, internal consistency assessed by Cronbach alpha was documented most often followed by interrater reliability assessed as percentage agreement.

Internal consistency may have limited use given that some maltreatment behaviours may not be related. For example, some forms of neglect may not relate to other forms of neglect nor with other types of child maltreatment. Due to these complexities of internal consistency, this measure must be interpreted with caution. ${ }^{84,112}$ In general, surveying youth yields data that are only minimally affected by recall bias. ${ }^{113}$ Of course, validity may still be compromised by social desirability bias, due to the delicate nature of maltreatment questions. However, research revealed few difficulties arising from the sensitivity of the questions. ${ }^{24,53,61}$ The different developmental stage of the reviewed measures may partially explain why few psychometric properties of child maltreatment measures were reported. Newer measures were often adjusted for cultural and language adaptations; continued testing should lead to improvements in data accuracy.

Data quality and response rate are also affected by technical aspects of data collection and the setting in which it takes place. Most of the studies reviewed were based on surveys conducted within schools-where all students were responding to the same survey at the same timeand thus obtained high response rates. However, willingness to participate was not universal among schools, for reasons unrelated to child maltreatment questions. ${ }^{33,53,57}$ Research suggests that among students, maximizing privacy and guaranteeing anonymity are effective in ensuring high response rates. ${ }^{45}$ The importance of privacy was also underscored in a study in which younger participants (age 10 years) found responding to a survey more upsetting in the presence of the caregiver than when they were alone. ${ }^{114}$

The means by which consent for survey participation is obtained can also affect the response rate; the requirement for consent from parents may discourage participation, especially among youth who have experienced child maltreatment. ${ }^{47,51,115}$ Parental passive consent was used in multiple surveys to increase response rate and avoid sampling bias potentially related to active parental consent. ${ }^{65,80,106}$ In one study, researchers designed and used a modified consent procedure in case any of the participants were being maltreated by a primary caregiver. ${ }^{58}$

\section{Ethical considerations}

Eliciting information about experience with child maltreatment is a delicate matter; the manner in which questions are worded is an important consideration. Even a survey's name can potentially evoke anxiety and may lead to unwillingness to participate (e.g. stronger emotions may be triggered by reference to a survey on "child maltreatment" than to one on "child health"). Similarly, the language used in questions about experience with child maltreatment can affect the respondent. Sensitivity to the potential for adverse reactions is critical, as is a clear statement assuring the anonymity and confidentiality of the survey. However, the review found that some researchers included a confidentiality breach procedure in the consent form if a youth was in need of protection, which allowed automatic referral of participants to appropriate authorities..$^{50,75,81}$ This strategy did not negatively affect response rate. ${ }^{75,81}$

This review suggests that youth are generally comfortable in answering questions about their experience with child maltreatment. ${ }^{12,14,71,116}$ One study showed that $4.6 \%$ of youth reported being upset when answering a child maltreatment survey, but of these, $95.3 \%$ said they would nonetheless participate in a similar survey. ${ }^{116}$ Interestingly, from the $17.3 \%$ of participants who had reported experiences classified as high-risk, only $2 \%$ were referred for counselling services ${ }^{116}$. In addition, one article mentioned that sexual abuse questions were not answered by $11 \%$ of respondents, but did not offer adequate information to assess if non-responses were higher for sexual abuse questions than for others. ${ }^{2}$ However, several researchers concluded that the potential benefits from the information obtained from child maltreatment questions exceed the potential respondent distress., ${ }^{7,16,117}$ An earlier study in adolescents comparing stress produced by child maltreatment questions with that arising from questions about school marks found no differences. ${ }^{118}$

\section{Limitations}

Several limitations affect this review. First, inconsistencies in child maltreatment measures across surveys-and sometimes even within different cycles of the same survey-made classification challenging. Second, some articles that otherwise met the criteria for inclusion in the review were excluded on the basis of insufficient methodological information. For instance, papers failing to identify the relationship of the perpetrator to the victim or to distinguish between exposure to family violence and community violence were not included. Third, prevalence estimates were not provided in a standardised way. Fourth, steps taken to increase the response rate could often not be distinguished from those taken to increase the comfort of the respondent, so they were considered in 
combination. Fifth, measures had often been modified from their original version, and results of validity and reliability testing of the modified versions were not usually provided. Sixth, certain segments of the population were excluded either because they do not attend school or were absent the day of data collection. Seventh, the exclusion of articles in languages other than English limited the international scope of the review. Eighth, only peerreviewed articles have been included in the review, which may introduce publication bias. Finally, limiting the review to the articles without examining the underlying surveys likely resulted in the exclusion of some relevant information.

\section{Implications}

This review shows that child maltreatment is a common concern across a range of societies and cultures although Canadian national data were missing. As evidenced by the large number of self-report surveys and studies asking youth about their level of comfort, data on child maltreatment can be collected responsibly and ethically from youth in a way that protects their health and well-being. ${ }^{14,116}$ Surveillance and research on child maltreatment would benefit greatly from the routine inclusion of questions on the subject in populationbased self-report health surveys. Hovdestad and Tonmyr ${ }^{119}$ stressed the importance of setting the stage for inclusion of child maltreatment questions in surveys by a) preparing for early resistance, b) building a broad base of support, c) having knowledge of the current literature (including issues addressed in this article), and d) being willing to compromise and showing determination. Data collected on a regular basis would provide the opportunity for enhancing our understanding of the burden and the factors that are correlated with child maltreatment. ${ }^{120}$ Schools could be an excellent venue for data collection due to high participation in these surveys and high enrolment among youth. After required discussions and agreements with the appropriate school authorities, it is easy to have procedures in place to obtain youth consent to participate and parents/ caregivers passive consent. To maximize the quality of the data, measures used in collection should undergo reliability and validity testing, and all aspects of the survey methodology should be sound. Behaviourbased questions with response options capturing severity and frequency are also recommended.
Protocols to address potential participant distress should be established, and interviewers should be trained to conduct research sensitively and appropriately. Effective means of evaluating participant distress should be refined and applied, and the results of such evaluations should inform questionnaire design and language. Surveys should be conducted according to a strict code of ethics, the overarching goals of which should be the protection of privacy and confidentiality, and respect for respondents.

\section{Acknowledgements}

The authors gratefully acknowledge assistance with the preparation of this manuscript from Kathryn Wilkins, Tanya Pires, Tanya Lary and Jaskiran Kaur, who provided useful comments on earlier drafts.

\section{Conflicts of interest}

There is no conflict to declare.

\section{Authors' contributions and statement}

L.T. conceived and designed the study. C.W., L.T., and J.L. wrote the paper: L.T. wrote the protocol, with input from the others. J.L., L.T., C.W., J.D., and S.A. extracted and categorized the data. L.T. led the evaluative component.

The content and views expressed in this article are those of the authors and do not necessarily reflect those of the Government of Canada.

\section{References}

1. Saewyc EM, Tonkin R. Surveying adolescents: focusing on positive development. Paediatr Child Health. 2008; 13(1):43-7.

2. Asgeirsdottir BB, Sigfusdottir ID, Gudjonsson GH, Sigurdsson JF. Associations between sexual abuse and family conflict/violence, self-injurious behavior, and substance use: the mediating role of depressed mood and anger. Child Abuse Negl. 2011;35(3): 210-19. doi: 10.1016/j.chiabu.2010.12 .003 .

3. Basile KC, Black MC, Simon TR, et al. The association between self-reported lifetime history of forced sexual intercourse and recent health-risk behaviors: findings from the 2003 national youth risk behavior survey. J Adolesc Health. 2006;39(5):752.e1-7.
4. Begle AM, Hanson RF, Danielson CK, McCart MR, Ruggiero KJ, Amstadter $\mathrm{AB}$, et al. Longitudinal pathways of victimization, substance use, and delinquency: findings from the national survey of adolescents. Addict Behav. 2011;36(7):682-9. doi: 10.1016 /j.addbeh.2010.12.026.

5. Rhodes AE, Boyle MH, Bethell J, Wekerle C, Goodman D, Tonmyr L, et al. Child maltreatment and onset of emergency department presentations for suicide-related behaviours. Child Abuse Negl. 2012;36(6):542-51.

6. Hovdestad W, Campeau A, Potter D, Tonmyr L. A systematic review of childhood maltreatment assessments in population-representative surveys since 1990. PLoS ONE. 2015;10(5). doi: 10.1371/journal.pone.0123366. eCollection 2015.

7. Tonmyr L, Hovdestad WE, Draca J. Commentary on Canadian child maltreatment data. J Interpers Violence. 2014;29(1):186-97.

8. Elliott K, Urquiza A. Ethnicity, culture, and child maltreatment. J Soc Issues. 2006;62(4):787-809.

9. Garbarino J, Ebata A. The significance of ethnic and cultural differences in child maltreatment. J Marriage Fam. 1983;45:773-83. doi: 10.2307/351790.

10. Smith C. Ethical considerations for the collection, analysis and publication of child maltreatment data. International Society for the Prevention of Child Abuse and Neglect. 2016.

11. Riley AW. Evidence that school-age children can self-report on their health. Ambul Pediatr. 2004;4(4): 371-6. doi 10.1367/A03-178R.1

12. Finkelhor D, Omrod R, Turner $H$, Hamby S. The victimization of children and youth: a comprehensive national survey. Child Maltreat. 2005; 10(1):5-25.

13. Finkelhor D, Turner HA, Shattuck A, Hamby SL. Violence, crime and abuse exposure in a national sample of children and youth: an update. JAMA Paediatr. 2013;167(7):614-21. doi: 10.1001/jamapediatrics.2013.42. 
14. Helweg-Larsen K, Boving-Larsen $\mathrm{H}$. Ethical issues in youth surveys: potentials for conducting a national questionnaire study on adolescent schoolchildren's sexual experiences with adults. Am J Public Health. 2003;93(11);1878-82.

15. Helweg-Larsen K, Sundaram V, Curtis $T$, Boving Larsen $H$. The Danish Youth Survey 2002: Asking young people about sensitive issues. Int $\mathrm{J}$ Circumpol Heal. 2004;63(S2):147-152.

16. Colin-Vézina D, De La SablonniereGriffin M, Palmer AM, Milne L. A preliminary mapping of individual, relational and social factors that impede disclosure of childhood sexual abuse. Child Abuse Negl. 2015;43:123-34. doi: 10.1016/j.chiabu .2015.03.010

17. Amaya-Jackson L, Socolar RRS, Hunter W, Runyan DK, Colindres, R. Directly questioning children and adolescent about maltreatment: a review of surveys measures used. J Interpers Violence. 2000;15(7):725-59.

18. Moher D, Liberati A, Tetzlaff J, Altman DG. The PRISMA Group (2009) Preferred reporting items for systematic reviews and meta-analyses: The PRISMA statement. PLOS Medicine. 2009;6(7):e1000097.

19. Fergusson DM, McLeod GF, Horwood LJ. Childhood sexual abuse and adult developmental outcomes: findings from a 30-year longitudinal study in New Zealand. Child Abuse Negl. 2013;37(9):664-74.

20. MacMillan HL, Tanaka M, Duku E, Vaillancourt T, Boyle MH. Child physical and sexual abuse in a community sample of young adults: results from the Ontario Child Health Study. Child Abuse Negl. 2013;37(1):14-21. doi: 10.1016/j.chiabu.2012.06.005.

21. Public Health Agency of Canada. Canadian Incidence Study of Reported Child Abuse and Neglect: Major Findings. Ottawa (ON): Public Health Agency of Canada; 2010.

22. Saewyc EM, Chen W. To what extent can adolescent suicide attempts be attributed to violence exposure? A population-based study from western Canada. Can J Commun Ment Health. 2013;32(1):79-94.
23. Wong WCW, Leung PWS, Tang CSK, et al. To unfold a hidden epidemic: prevalence of child maltreatment and its health implications among high school students in Guangzhou, China. Child Abuse Negl. 2009;33(7):441-50. doi: 10.1016/j.chiabu.2008.02.010.

24. Helweg-Larsen K, Larsen, HB. The prevalence of unwanted and unlawful sexual experiences reported by Danish adolescents: results from a national youth survey in 2002. Acta Paediatr. 2006;95:1270-6. doi: 10.1080 /08035250600589033.

25. Borges G, Benjet C, Medina-Mora ME, Orozco R, Molnar BE, Nock MK. Traumatic events and suicide-related outcomes among Mexico City adolescents. J Child Psychol Psyc. 2008; 49(6):654-66. doi: 10.1111/j.1469-7610 .2007.01868.x.

26. Priebe G, Svedin CG. Online or offline victimisation and psychological well-being: a comparison of sexualminority and heterosexual youth. Eur Child Adoles Psyc. 2012;21(10):56982. doi: 10.1007/s00787-012-0294-5.

27. Pineda-Lucatero AG, Trujillo-Hernández B, Millán-Guerrero RO, Vásquez C. Prevalence of childhood sexual abuse among Mexican adolescents. Child Care Health Dev. 2009;35(2):184-9.

28. Finkelhor D, Turner H, Ormrod R, Hamby SL. Violence, abuse, and crime exposure in a national sample of children and youth. Pediatrics. 2009;124(5):1411-23.

29. Chan KL, Yan E, Brownridge DA, Ip P. Associating child sexual abuse with child victimization in China. J Pediatr. 2013;162:1028-34. doi: 10.1016/j.jpeds .2012.10.054.

30. Pettifor AE, Rees HV, Kleinschmidt I, Steffenson AE, MacPhail C, HlongwaMadikizela L, et al. Young people's sexual health in south Africa: HIV prevalence and sexual behaviors from nationally representative household survey. AIDS. 2005;19:1525-34.

31. Leung PWS, Wong WCW, Chen WQ, Tang CSK. Prevalence and determinants of child maltreatment among high school students in southern China: a large scale school based survey. Child Adolesc Psychiatry Ment Health. 2008;2:27. doi: 10.1186/1753 -2000-2-27.
32. Aberle N, Ratković-Blažević V, MitrovićDittrich D, Coha R, Stoić A, Bublić J, et al. Emotional and physical abuse in family: survey among high school adolescents. Croat Med J. 2007;48(2): 240-8.

33. Ellonen $N$, Kääriäinen $J$, Sariola $H$, Helweg-Larsen K, Larsen HB. Adolescents' experiences of parental violence in Danish and Finnish families: a comparative perspective. J Scand Stud Criminol Crime Prev. 2011;12(2): 173-97. doi: 10.1080/14043858.2011 .622076 .

34. Chan KL. Children exposed to child maltreatment and intimate partner violence: a study of co-occurrence among Hong Kong Chinese families. Child Abuse Negl. 2011;35:532-42. doi: 10.1016/j.chiabu.2011.03.006.

35. Seedat S, Nyamai C, Njenga F, Vythilingum, B, Stein DJ. Trauma exposure and post-traumatic stress symptoms in urban African schools: survey in Cape Town and Nairobi. Brit J Psychiat. 2004;184:169-75.

36. Breiding MJ, Mercy JA, Gulaid J, Reza A, Hleta-Nkambule N. A national survey of childhood physical abuse among females in Swaziland. J Epidemiol Glob Health. 2013;3(2):7381. doi: 10.1016/j.jegh.2013.02.006.

37. Cyr K, Chamberland C, Clement M, Lessard G, Wemmers J, Collin-Vézina $\mathrm{D}$, et al. Polyvictimization and victimization of children and youth: results from a population survey. Child Abuse Negl. 2013;37:814-20. doi: 10.1016/j.chiabu.2013.03.009.

38. Lepistö S, Åstedt-Kurki P, Joronen K, Luukkaala T, Paavilainen E. Adolescents' experiences of coping with domestic violence. J Adv Nurs. 2010; 66(6):1232-45. doi: 10.1016/j.chiabu .2013.03.009

39. Bussmann K. Evaluating the subtle impact of a ban on corporal punishment of children in Germany. Child Abuse Rev. 2004;13(5):292-311. doi: 10.1002/car.866.

40. McLaughlin KA, Green JG, Gruber MJ, Sampson NA, Zaslavsky AM, Kessler RC. Childhood adversities and first onset of psychiatric disorders in a national sample of US adolescents. Arch Gen Psychiatry. 2012;69(11): 1151-60. doi: 10.1001/archgenpsychiatry .2011.2277. 
41. Kassis W, Artz S, Scambor C, Scambor E, Moldenhauer S. Finding the way out: a non-dichotomous understanding of violence and depression resilience of adolescents who are exposed to family violence. Child Abuse Negl. 2013;37(2):181-9. doi: 10.1016/j. chiabu.2012.11.001.

42. Horta RL, Horta BL, Costa AWN, et al. Lifetime use of illicit drugs and associated factors among Brazilian schoolchildren, National Adolescent School-based Health Survey (PeNSE 2012). Revista Brasileira de Epidemiologia. 2014;17:s31-45. doi: 10.1590/1809-4503201400050004.

43. Malta DC, Mascarenhas MDM, Dias AR, Prado RRd, Lima CM, Silva, MM.A da, et al. Situations of violence experienced by students in the state capitals and the Federal District: results from the National Adolescent School-based Health Survey (PeNSE 2012). Revista Brasileira de Epidemiologia. 2014;17:s158-71.

44. Tonkin RS, Murphy A, Chittenden M, et al. Health Youth Development: Highlights from the 2003 Adolescent Health Survey. [Internet]. Vancouver (BC): McCreary Centre Society; 2004. [cited 2016 January 14] Available from: http://www.mcs.bc.ca/pdf/AHS -3_provincial.pdf

45. Tonkin RS. British Columbia Youth Health Trends: A Retrospective, 19922003. [Internet]. Vancouver (BC): McCreary Centre Society; 2005. [cited 2016 January 14] Available from: http://www.mcs.bc.ca/pdf/AHS -Trends-2005-report.pdf

46. Saewyc E, Wang N, Chittenden M, Murphy A. Building resilience in vulnerable youth. [Internet]. Vancouver (BC): McCreary Center Society; 2006. [cited 2016 Jan 14]. Available from: http://www.mcs.bc.ca/pdf/vulnerable _youth_report.pdf

47. Saewyc E, Green R. Survey Methodology for the 2008 BC Adolescent Health Survey IV. Vancouver (BC): McCreary Center Society; 2009.

48. Lau JTF, Kim JH, Tsui HY, Phil M, Cheung A, Lau $\mathrm{M}$ et al. The relationship between physical maltreatment and substance use among adolescents: a survey of 95, 788 adolescents in Hong Kong. J Adolesc Health. 2005;37:110-9. doi: 10.2471 /BLT.14.141970.
49. Tang CS. Corporal punishment and physical maltreatment against children: a community study on Chinese parents in Hong Kong. Child Abuse Negl. 2006;30:893-907.

50. Ajdukovic M, Susac, N, Rajter M. Gender and age differences in prevalence and incidence of child abuse in Croatia. Croat Med J. 2013;53:469-79. doi: $10.3325 / \mathrm{cmj} .2013 .54 .469$.

51. Helweg-Larsen K, Frederiksen ML, Larsen HB. Violence, a risk factor for poor mental health in adolescence: a Danish nationally representative youth survey. Scand J Public Health. 2011;39(8): 849-56. doi: 10.1177/1403494811421638.

52. Frederiksen ML, Helweg-Larsen K, Larsen HB. Self-reported violence amongst adolescents in Denmark: is alcohol a serious risk factor? Acta Paediatr. 2008;97(5):636-40. doi: 10.1111/j.1651-2227.2008.00735.x.

53. Van Gastel WA, Tempelaar W, Bun C, Schubart CD, Kahn RS, Plevier C, et al. Cannabis use as an indicator of risk for mental health problems in adolescents: a population-based study at secondary schools. Psychol Med. 2013;43(9):1849-56. doi: 10.1111/j .1651-2227.2008.00735.x.

54. Sariola H, Uutela A. The prevalence and context of family violence against children in Finland. Child Abuse Negl. 1992;16(6):823-32.

55. Ohene SA, Johnson K, AtunahJay S, Owusu A, Borowsky IW. Sexual and physical violence victimization among senior high school students in Ghana: risk and protective factors. Soc Sci Med. 2015;146:266-75. doi: 10.1016/j .socscimed.2015.10.019.

56. World Health Organization. Global School-Based Student Health Survey (GSHS) Purpose and Methodology. [cited 2017 oct 22] Available from: http://www.who.int/chp/gshs /methodology/en/

57. Fotiou A, Kanavou E, Richardson C, Ploumpidis D, Kokkevi A. Misuse of prescription opioid analgesics among adolescents in Greece: the importance of peer use and past prescriptions. Drugs: Educ Prev Polic. 2014; 21(5):357-69. doi: 10.3109/09687637 .2014.899989.
58. Flynn-O’Brien KT, Rivara FP, Weiss NS, et al. Prevalence of physical violence against children in Haiti: a national population-based cross sectional survey. Child Abuse Negl. 2016;51:154-62. doi: 10.1016/j.chiabu .2015 .10 .021 .

59. Patel V, Andrew G. Gender, sexual abuse and risk behaviours in adolescents: a cross-sectional survey in schools in Goa. Natl Med J India. 2001;14(5):263-7.

60. Mahram M, Hosseinkhani Z, Nedjat S, Aflatouni A. Epidemiologic evaluation of child abuse and neglect in school-aged children of Qazvin province, Iran. Iran J Pediatr. 2013;23(2): 159-64.

61. Okech JEA. A multidimensional assessment of children in conflictual contexts: the case of Kenya. Int J Adv Couns. 2012;34(4):331-48.

62. Frias SM, Erviti J. Gendered experiences of sexual abuse of teenagers and children in Mexico. Child Abuse Negl. 2014;38(4):776-87. doi: 10.1016 /j.chiabu.2013.12.001.

63. Ahmad N, Cheong SiewMan, Nurashikin Ibrahim, Azriman R. Suicidal ideation among Malaysian adolescents. (Supplement Issue: Malaysian school-based survey 2012.). Asia-Pac J Public Health. 2014;26(5): 63S-69S.

64. Ahmed A, Wan-Yen C, Marret MJ, et al. Child maltreatment experience among primary school children: A large scale survey in Selangor state, Malaysia. PLoS ONE. 2015;10(3).

65. Klein K, Boersma AA, Meyboomde Jong B, de Bruijn J. Child abuse: a common problem in Curacao? West Indian Med J. 2013;62(2):127-34.

66. Denny SJ, Grant S, Utter J, Robinson EM, Fleming TM, Milfont TL, et al. Health and well-being of young people who attend secondary school in Aotearoa, New Zealand: What has changed from 2001 to 2007? J Paediatr Child Health. 2011;47(4):191-7. doi: 10.1111/j.1440-1754.2010.01945.x. 
67. Fleming $\mathrm{T}$, Watson $\mathrm{P}$, Robinson $\mathrm{E}$, Ameratunga S, Dixon R, Clark T, et al. Violence and New Zealand young people: findings of Youth 2000 - A National Secondary School Youth Health and Wellbeing Survey. Auckland: The University of Auckland, 2007.

68. Adolescent Health Research Group. Youth'07: The Health and Wellbeing of Secondary Schools Students in New Zealand. Auckland, New Zealand: The University of Auckland; 2008.

69. Fry D, Anderson J, Hidalgo RJT, Elizalde A, Casey T, Rodriguez R, et al. Prevalence of violence in childhood and adolescence and the impact on educational outcomes: evidence from the 2013 Peruvian national survey on social relations. Int Health. 2016;8(1):44-52.

70. Al-Quaiz AM, Raheel HM. Correlates of sexual violence among adolescent female in Riyadh, Saudi Arabia. Saudi Med J. 2009;30(6):829-34.

71. Al-Eissa MA, Saleheen HN, Almadani $\mathrm{S}$, et al. Determining prevalence of maltreatment among children in the kingdom of Saudi Arabia. Child Care Health Dev. 2016;42(4):565-71.

72. International Society for the Prevention of Child Abuse and Neglect (ISPCAN). ICAST-CH study tool. [cited 2016 Oct 7] Available from: http:// www.ispcan.org/page/ICAST

73. Rajindrajith S, Devanarayana NM, Lakmini C, et al. Association between child maltreatment and constipation: a school-based survey using Rome III criteria. J Pediatr Gastroenterol Nutr. 2014;58(4):486-90. doi: 10.1097/MPG .0000000000000249 .

74. Andersson N, Ho-Foster A. 13,915 reasons for equity in sexual offences legislation: a national school-based survey in South Africa. Int J Equity Health. 2008;7:20.

75. Waller R, Gardner F, Cluver L. Shared and unique predictors of antisocial and substance use behavior among a nationally representative sample of South African youth. AggressViolent Behav. 2014;19(6):629-36. doi: 10.1016 /j.avb.2014.09.002.
76. Young Carers Project South Africa. Teen Talk South Africa. [cited 2016 Oct 16] Available from: https://static1 .squarespace.com/static/54e3c4b3e4 b 02 a 415877 e $452 / t / 55 f 2$ e $1 \mathrm{ffe} 4 \mathrm{~b}$ 04671a3ecb62b/1441980927196/Teen + Talk + 1 + -ENGLISH-27-Jan-20101 .pdf

77. Mossige S, Ainsaar M, Svedin CG. The Baltic Sea Regional Study on Adolescent Sexuality. Oslo: Norwegian Social Research (NOVA); 2007.

78. Yen CF, Yang MS, Yang MJ, et al. Childhood physical and sexual abuse: prevalence and correlates among adolescents living in rural Taiwan. Child Abuse Negl. 2008;32:429-38. doi: 10.1016/j.chiabu.2007.06.003.

79. Sofuglu Z, Oral R, Aydin F, et al. Epidemiological study of negative childhood experiences in three provinces of Turkey. Türk Ped Ars. 2014; 49:47-56. doi: 10.5152/tpa.2014.838.

80. Jackson V, Browne K, Joseph S. The prevalence of childhood victimization experienced outside of the family: Findings from an English prevalence study. Child Abuse Negl. 2016;51:34357. doi: 10.1016/j.chiabu.2015.08.006.

81. Radford L, Corral S, Bradley C, Fisher $\mathrm{H}$. The prevalence and impact of child maltreatment and other types of victimisation in the UK: Findings from a population survey of caregivers, children and young people and young adults. Child Abuse Negl. 2013;37:801-813.

82. Finkelhor D, Omrod R, Turner H, Hamby S. School, police, and medical authority involvement with children who have experienced victimization. Arch Pediat Adol Med. 2011;165(1): 9-15. doi: 10.1001/archpediatrics.2010 .240 .

83. Mitchell KJ, Finkelhor D, Wolak J, Ybarra ML, Turner H. Youth internet victimization in a broader victimization context. J Adolesc Health. 2011; 48(2):128-34. doi: 10.1016/j.jadohealth .2010.06.009.

84. Finkelhor D, Hamby SL, Omrod R, Turner H. The Juvenile Victimisation Questionnaire: reliability, validity and national norms. Child Abuse Negl. 2005;29(4):383-412. doi: 10.1016/j .chiabu.2004.11.001.
85. Hamby S, Finkelhor D, Turner $\mathrm{H}$. Perpetrator and victim gender patterns for 21 forms of youth victimization in the National Survey of Children's Exposure to Violence. Violence Vict. 2013;28(6):915-39.

86. Hamby SL, Finkelhor D, Ormrod RK, Turner HA. The Juvenile Victimization Questionnaire (JVQ) Administration and Scoring Manual. Durham $(\mathrm{NH})$ : Crimes Against Children Research Center; 2005.

87. Finkelhor D, Vanderminden J, Turner H, Hamby S, Shattuck A. Child maltreatment rates assessed in a national household survey of caregivers and youth. Child Abuse Negl. 2014;38(2): 1421-35.

88. Finkelhor D, Turner HA, Shattuck A, Hamby SL. Prevalence of childhood exposure to violence, crime, and abuse: results from the National Survey of Children's Exposure to Violence. JAMA Pediatr. 2015;169(8): 746-54. doi: 10.1001/jamapediatrics .2015.0676.

89. Finkelhor D, Shattuck A, Turner H, Hamby S. A revised inventory of Adverse Childhood Experiences. Child Abuse Negl. 2015;48:13-21. doi: 10.1016/j.chiabu.2015.07.011.

90. Strauss MA. Measuring intrafamily conflict and violence: the Conflict Tactics (CT) Scales. J Marriage Fam. 1979;41(1):75-86. doi: 10.2307/351733.

91. McLaughlin KA, Koenen KC, Hill ED, Petukhova M, Sampson NA, Zaslavsky AM. Trauma exposure and posttraumatic stress disorder in a national sample of adolescents. J Am Acad Child Adolesc Psychiatry. 2013;52(8): 815-30.e14. doi: 10.1016/j.jaac.2013 .05.011.

92. McChesney GC, Adamson G, Shevlin M. A latent class analysis of trauma based on a nationally representative sample of US adolescents. Soc Psychiatry Psychiatr Epidemiol. 2015; 50(8):1207-17. doi: 10.1007/s00127 $-015-1075-5$.

93. Merikangas KR, Avenevoli, S, Costello J, Kortez, D, Kessler RC. The National comorbidity survey adolescent supplement (NCS-A): 1 Background and measures. J Am Acad Child Adolesc Psychiatry. 2009;48(4):367-9. doi: 10.1097/CHI.0b013e31819996f1. 
94. Danielson CK, Macdonald A, Amstadter AB, Hanson RF, de Arellano MA, Saunders BE, Kilpatrick DG. Risky behaviors and depression in conjunction with-or in the absence of-lifetime history of PTSD among sexually abused adolescents. Child Maltreat. 2010;15(1):101-7. doi: 10.1177 /1077559509350075.

95. Hawkins AO, Danielson CK, de Arellano MA, Hanson RF, Ruggiero KJ, Smith DW, et al. Ethnic/racial differences in the prevalence of injurious spanking and other child physical abuse in a national survey of adolescents. Child Maltreat. 2010;15(3):2429. doi: $10.1177 / 1077559510367938$.

96. McCauley JL, Danielson CK, Amstadter AB, Ruggiero KJ, Resnick HS, Hanson RF, et al. The role of traumatic event history in non-medical use of prescription drugs among a nationally representative sample of US adolescents. J Child Psychol Psyc. 2010;51(1):84-93. doi: 10.1111/j.1469 -7610.2009.02134.x.

97. McCart MR, Zajac K, Danielson CK, Strachan M, Ruggiero KJ, Smith DW, et al. Interpersonal victimization, posttraumatic stress disorder, and change in adolescent substance use prevalence over a ten-year period. J Clin Child Adolesc Psyc. 2011;40(1): 136-43. doi: 10.1080/15374416.2011 .533411 .

98. Andrews AR3rd, Jobe-Shields L, Lopez CM, Metzger IW, de Arellano MAR, Saunders B, et al. Polyvictimization, income, and ethnic differences in trauma-related mental health during adolescence. Soc Psychiatry Psychiatr Epidemiol. 2015; 50(8):1223-34. doi: 10.1007/s00127 $-015-1077-3$.

99. Haley CC, Hedberg K, Leman RF. Disordered eating and unhealthy weight loss practices: which adolescents are at highest risk? J Adolesc Health. 2010;47(1):102-5.

100. Oregon Public Health Division. 2005 results. Oregon Healthy Teen Survey [Internet]. Portland (OR): Oregon Health Authority; 2005 [cited 2016 May 5]. Available from: https://public.health .oregon.gov/BirthDeathCertificates /Surveys/OregonHealthyTeens/2005 /Pages/index.aspx
101. Alriksson-Schmidt AI, Armour BS, Thibadeau JK. Are adolescent girls with a physical disability at increased risk for sexual violence? J Sch Health. 2010;80(7):361-7. doi: 10.1111/j.1746 $-1561.2010 .00514 . x$.

102. Eaton DK, Kann L, Kinchen S, Ross J, Hawkins J, Harris WA, et al. Methodology of the youth risk behaviour surveillance - United States, 2005. MMWR Surveill Sum. 2006; 55:1-108.

103. Brener ND, Kann L, Kinchen SA, Grunbaum JA, Whalen L, Eaton D, et al. Methodology of the youth risk behavior surveillance system. MMWR Recomm Rep. 2004;53(RR12):1-14.

104. Howard DE, Wang MQW. Psychosocial correlates of U.S. adolescents who report a history of forced sexual intercourse. J Adolesc Health. 2005;36(5): 372-9. doi: 10.1016/j.jadohealth.2004 .07.007.

105. Lippe J, Brener N, Kann L, Kinchen S, Harris WA, McManus T, et al. Youth risk behaviour surveillance - Pacific Island United States territories, 2007. MMWR Surveill Summ. 2008;57(12): 28-56.

106. Peleg-Oren N, Cardenas GA, Comerford M, Galea S. Exploratory study on the association between interpersonal violence experiences and alcohol use among adolescents. Soc Work Res Sep. 2013;37(3):277-85. doi: 10.1093 /swr/svt016.

107. Brown DW, Riley L, Butchart A, Meddings DR, Kann L, Harvey AP. Exposure to physical and sexual violence and adverse health behaviours in African children: results from the Global School-based Student Health Survey. Bull World Health Organ. 2009;87(6):447-55. doi: 10.2471/BLT .07 .047423 .

108. Kassis W, Puhe H. Data Protection and Code of Research Ethics. Osnabruck, Germany: University of Osnabruck; 2009.

109. Durant J, Ensom R. Physical punishment of children: lessons from 20 years of research. Can Med Assoc J. 2012;184(12):1373-7. doi: 10.1503 /cmaj.101314.
110. Clément ME, Berube A, Chamberland C. Prevalence and risk factor of child neglect in the general population. Public Health. 2016;138:86-92. doi: 10.1016/j.puhe.2016.03.018.

111. Kaufman Kantor G, Holt MK, Mebert CJ, Straus MA, Drach KM, Ricci LR, et al. Development and preliminary psychometric properties of the multidimensional neglectful behavior scale child report. Child Maltreat. 2004;9(5):409-28. doi. 10.1177 /1077559504269530.

112. Turner RJ, Wheaton B. Checklist measurement of stressful life event. In: Cihen S, Kessler RC, Underwood GL, editors. Measuring stress: a guide for health and social scientists. Oxford University Press; 1997:29-53.

113. Arata CM, Langhinrichsen-Rohling J, Bowers D, O'Brien N. Differential correlates of multi-type maltreatment among urban youth. Child Abuse Negl. 2007;31(4):393-415.

114. Ybarra ML, Langhinrichsen J, Friend J, Dienner-West M. Impact of asking sensitive questions about violence to children and adolescents. J Adolesc Health. 2009;45:499-507. doi: 10.1016 /j.jadohealth.2009.03.009.

115. Langhinrichsen-Rohling J, Arata C, O'Brien N, Bowers D, Klibert, J. Sensitive research with adolescents: just how upsetting are self-report surveys anyways? Violence and Victims 2006;21(4):425-444.

116. Finkelhor D, Vanderminden J, Turner H, Hamby S, Shattuck A. Upset among youth in response to questions about exposure to violence, sexual assault and family maltreatment. Child Abuse Negl. 2014; 38(2):217-23. doi: 10.1016/j.chiabu .2013.07.021.

117. Zajac L, Ruggieor KJ, Smith DW, Saunders BE, Kilpatrick DG. Adolescent distress in traumatic stress research: Data from the National Survey of AdolescentsReplications. J Trauma Stress. 2011; 24(2):226-9. doi: 10.1002/jts.20621.

118. DeMarni Cromer L, Freyd JJ, Binder AK, De Prince AP, Becker-Blease K. What's the risk in asking? Participants' reaction to trauma history questions compared with reaction to other personal questions. Ethics Behav. 2006;16:347-62. doi: 10.1207/ s15327019eb1604_5. 
119. Hovdestad W, Tonmyr L. Proposal of childhood maltreatment questions for inclusion on a Canadian national health survey: notes from the process. In Gray J, editor. World Perspectives on Child Abuse. 9th ed. International Society for the Prevention of Child Abuse and Neglect (ISPCAN);2010:43-8.

120. Tonmyr L, Hovdestad W. Public health approach to child maltreatment. J Paediatr Child Health. 2013; 18(8):411-3. 